\title{
《教育原理》课程内容与教学方法探究
}

\author{
王华清 \\ 云南师范大学
}

DOI:10.32629/jief.v2i11.2390

[摘 要] 针对当前《教育原理》课程教学现状, 本文从《教育原理》课程的简单介绍; 《教育原理》课程教学中存在的困境; 《教育原理》棵 程内容以及教学方法的探究四个方面进行阐述，旨在提高课程教学质量，推动课程的长久发展。

[关键词] 教育原理; 课程内容; 教学方法

中图分类号：G642 文献标识码：A

《教育原理》作为一门课程, 有着稳定的学科结构和教学内容, 学生 在学习过程中, 不仅可以了解《教育原理》课程中涉及的内容, 区分该 课程与其他学科之间的区别, 而且可以提升自我, 发展教育素养, 为日 后的发展奠定坚实的基础。在现实中，想要提高《教育原理》课程的教 学质量与教学水平, 就要在熟悉课程内容的基础上探究多种现代化的教 学方法, 并将其进行合理的运用, 只有这样才能够获得良好的教学效果, 满足社会发展所需, 实现培养教育理论研究者和教育管理工作者的目标。

\section{1 《教育原理》课程的简单介绍}

通俗来讲, 《教育原理》就是一门探索教育事理的学科, 教学的侧重 点应体现在理论知识的讲解和传授上, 但要加强与学生实际经验的联系, 唯有学生熟练掌握相关理论知识, 才能够更好地进行实践。此外, 因不 同专家、学者对《教育原理》课程的理解存在一定的差异, 所以教材和 著作也会有不同的版本，比如说陈桂生的《教育原理》、袁振国的《教育 原理》、冯建军的《当代教育原理》, 相关著作包括柏拉图的《理想国》、 约翰・杜威的《民主主义与教育》、卢梭的《爱弥尔》等。这些珍贵的教 材和著作不仅可以成为学生学习上的精神食粮, 而且可以为教师的授课 提供帮助, 成为重要的教学资源。

\section{2 当前《教育原理》课程教学中存在的问题}

2.1 教学目标和教学方案具有一定的缺陷

为保证《教育原理》课程教学的顺利开展与实施, 促进教学效果的 提升, 多数教师在教学前都会根据教学内容制定教学方案, 明确教学目 标, 但在具体应用中却发现各种各样的问题和缺陷, 比如说, 教师的教 学思路及内容与教学方案脱轨, 没有围绕方案中的相关内容进行授课, 这样不仅会降低教学方案的制定价值, 而且会影响教学目标的实现。

\section{2 教师队伍的整体质量偏低}

《教育原理》课程质量与效果的提升, 除了与教学目标的确立, 教学 方案的详细制定有关外, 教师的个人素养同样重要。从当前的情况来看, 存在着教师队伍整体质量偏低的问题：首先，传统的课程教育思想根深 蒂固, 缺少实质性的创新, 难以满足现代化学生对学习的追求; 其次, 方案的制定过于系统, 无法起到实质性的作用; 再次, 教学模式一成不
变, 教学方法枯燥单一; 最后, 评价机制缺少科学性与规范性, 难以对 学生进行综合性评判。

\section{3 学生的参与度不高}

学生作为《教育原理》课程教学的主体, 他们的参与热情和学习的 积极性将直接影响教学质量和效果。然而, 从现阶段的教学情况来看, 学生的参与热情并不高涨, 主要原因在于教师的授课方式过于呆板。虽 然《教育原理》课程教学是以理论知识为主, 但如果教师使用 “照本宣 读” 或其他被动式的教学手段, 就会使学生失去学习的兴趣和耐心, 甚 至产生厌学心理, 这对学生自身能力和课程质量的提升是十分不利的。

\section{3 《教育原理》课程内容}

陈桂生的《教育原理》(第二版) 中的课程内容有: 教育的内部结构、 教育与社会、教育是什么、中国特色社会主义教育。

袁振国的《教育原理》中的课程内容分为两部分：第一部分为说明 部分, 该部分中的课程内容有: 教育的历史变迁及其演讲、教育的本质、 教育的基本功能、学校教育制度与教育体制改革、教育目的、教育内容、 教师与学生、教育活动、课程、教学理论、学生教育理论; 第二部分为 文本部分, 课程内容包括教学方法和教学过程。

冯建军的《当代教育原理》中的课程内容包括：当代教育应该是什 么、人类的发展与教育、个体生命发展与教育、教育目的、教育主体、 教育系统的产生与发展、社会发展与教育发展、当代社会与当代教育。

\section{4 《教育原理》课程教学方法探究}

\section{1 对话式教学法}

相比于其他课程而言, 《教育原理》有着较强的理论性, 这就要求学 生在学习中要深入理解并掌握这些理论知识, 只有这样才能够灵活运用 于理论指导和实践当中去。但如果运用灌输式、填鸭式等教学方法, 不 仅无法激发学生的学习兴趣, 调动他们的积极性, 而且会使课程存在严 重的滞后性。因此, 在实际教学中, 教师要注重教学理念的改革和教学 方法的创新, 根据学生的实际所需, 引入适当的教学方法。其中, 对话 式教学的有效运用, 在革新教学方法的同时, 还能够增加师生之间的沟 通和交流, 在老师的帮助和小组积极的探讨下, 学生的学习理解能力和 
思辨能力会得到有效的提升。例如, 在教学陈桂生的《教育原理》(第二 版）中的 “教育与社会” 时, 教师首先要将学生视为课堂的主体, 本着 尊重、谦虚、平等的态度与学生交流, 然后为其布置学习任务, 如 “教 育与传播媒介” “教育与闲暇” 中涉及的有关内容及问题。每当学生积极 探讨相关问题时, 教师不要置若罔闻, 而是要主动参与, 不仅要鼓励和 肯定学生的对问题的探讨结果, 而且要给予他们适当的帮助。如此一来, 既能够建立融洽的师生关系, 营造良好的学

习氛围, 还能够加深学生对知识的理解和极易, 使其养成积极思考的好 习惯。

\section{2 问题式教学法}

通过问题的提出、思考、探讨以及交流, 不但可以帮助学生迅速解 决问题, 找出自己在解决习题时存在的不足之处, 而且可以培养其自主 学习、独立思考和解决问题等方面的能力。比如说, 在 “教育活动” 的 报告中, 教师要认真倾听学生的报告内容, 记录学生在报告中存在的问 题, 或是本应报告清楚却模棱两可的关键性问题, 然后采取提问的方式 让学生进行回答, 如果是一些缺陷性问题, 应告知学生在课后进行补充。 在这种教学方法的积极作用下, 学生的学习能力和认知能力会在循序渐 进中得到提升, 认真、严禁的态度也会得到培养。教师提出问题, 学生 探究、回答问题的过程就是学生进步与成长的过程, 这对他们未来的发 展将会大有裨益。

\section{3 现代化教学法}

近年来, 在信息化技术与网络化技术日益发展的背景下, 各领域要 想在愈演愈烈的市场竞争中占据主导地位, 就要依托于现代化技术, 教 育领域也不例外。因此, 在《教育原理》课程教学中, 教师要认识到现 代化技术的重要性, 将其进行合理的应用, 如多媒体、微课、慕课等。 一方面, 现代化教学法的运用, 能够突破空间和时间的束缚, 学生在任 何时间、任何地点都可以对课程内容进行学习; 另一方面, 相比于其他 教学方法而言, 现代化教学法更能调动学生的积极性, 提高他们的课堂 参与度。此外, 现代化教学法可以拓展学生的学习渠道, 丰富他们的学 习资源, 为学生提供便利的服务。对于教师而言, 现代化教学法同样发 挥着重要的作用, 教师可以到相应的平台中下载海量的教学资源, 然后 进行整合, 并以微课的形式进行传授, 这样既可以提高学生的理解能力 和思维能力, 又能够促进教学水平与教学效果的提升。

\section{4 实践教学法}

众所周知在, 实践是检验真理的唯一标准。在《教育原理》课程教 学中, 如果教师将教学的侧重点放在理论知识的讲解上, 忽视了实践的 重要性, 那么教学效果将会与教学目标相背而驰, 学生在今后的工作中 也是空有一身基础学原理, 却不会进行灵活运用。因此, 在实际教学中, 教师既要重视理论知识的传授和细致入微的讲解, 又要注重实践教学法 的渗透, 联系教育实践开展相关的教育教学活动。具体来讲, 就是在传
授知识时, 要与学生的经验相结合, 只有这样学生才会有更为深刻的体 会和思考, 以便在日后的教育教学或管理实践中将所学知识进行灵活运 用。

4.5 重视教学的每一个环节

教学不仅仅是体现在课堂之上, 课前、课后的任意环节都可以称之 为教学。所以, 在《教育原理》课程教学中, 教师要重视教学中的每一 个环节, 并着手于以下几方面的内容: 首先, 根据课程内容制定详细的 教学计划、明确教学目标、精心备课, 同时以课程内容为基准选择适当 的教学方法; 其次, 认真履行自己的义务, 对学生的学习情况进行监督, 如课题研究、论文撰写等; 最后, 做好课后的评价工作, 耐心评阅学生 的各项作业, 指出作业中存在的不足之处, 并给予学生适当的帮助。唯 有教师重视教学中的各个环节, 充分发挥自己的主导作用对学生的进行 监督和引导, 才有可能保证教学质量及效果的提升, 以便为学生日后的 发展铺设出一条条康庄大道。

\section{5 结束语}

综上所述, 《教育原理》课程在培养优秀教育理论研究者和教育管理 工作者上做出了较大的贡献。但在实际的教学中却发现一定的问题, 若 想使存在的问题得以解决, 促进课程质量与效果的提升, 就需要在掌握 《教育原理》课程内容的同时, 注重多种教学方法的探究和应用, 如对话 式教学法、问题式教学法、现代化教学法等。唯有此, 才能够提高教学 水平, 实现学生在该课程领域中的个性化及全面发展。

\section{[参考文献]}

[1]论文写作网。“教育原理”课程内容与教学方法探析 [EB/OL].(2016-03-26)[2020-05-28].http://www.sxsky.net/benkelunwen/0 6075746_2.htm1.

[2]王凡,陈䂀, 邓徨. “教育原理”的课程内容与教学方法——教育经 济与管理专业硕士研究生的培养探讨 [J]. 科教导刊 (电子 版),2015,(2):56-57.

[3] 悦雅学社. 陈桂生《教育原理》(第二版) 总结 [EB/OL].(2010-10-24)[2020-05-28].http://blog.sina.com.cn/s/blog_6d57 2a0c0100mbhg.htm1.

[4]百度文库. 《教育原理》内容提要 [EB/OL].(2016-09-23)[2020-05-28].https://wenku.baidu.com/view/c8603 77530b765ce0508763231126edb6f1a762f.htm1.

[5]冯建军.关于 “教育原理” 的学科称谓与内容现状的研究 [J].教育 理论与实践,2007,27(04):001-005.

[6]刘晓琴. 教育原理和教育学原理的思考[ J]. 吉林省教育学院学 报,2010,(01):001-007.

作者简介: 王华清（1986.12-), 女, 汉族, 福建厦门人, 学生, 教育硕士，云南师范大学，研究方向：特殊教育 